OPEN ACCESS

Edited by:

Oliver Wirths,

University of Göttingen, Germany

Reviewed by:

Xiaogang Wu,

Institute for Systems Biology, USA

Theresa M. Casey,

University of Vermont, USA

${ }^{*}$ Correspondence:

Jean-Luc Morel

jean-luc.more/@u-bordeaux.fr

${ }^{\dagger}$ These authors have contributed equally to this work.

Received: 24 July 2016 Accepted: 06 December 2016 Published: 26 December 2016

Citation:

Pulga A, Porte Y and Morel J-L (2016) Changes in C57BL6 Mouse Hippocampal Transcriptome Induced by Hypergravity Mimic Acute Corticosterone-Induced Stress.

Front. Mol. Neurosci. 9:153. doi: 10.3389/fnmol.2016.00153

\section{Changes in C57BL6 Mouse Hippocampal Transcriptome Induced by Hypergravity Mimic Acute Corticosterone-Induced Stress}

\author{
Alice Pulga ${ }^{1,2 \dagger}$, Yves Porte ${ }^{1,2 \dagger}$ and Jean-Luc Morel ${ }^{1,2 *}$ \\ 1 Université de Bordeaux, Institut des Maladies Neurodégénératives, UMR 5293, Bordeaux, France, ${ }^{2}$ Centre National de la \\ Recherche Scientifique, Institut des Maladies Neurodégénératives, UMR 5293, Bordeaux, France
}

Centrifugation is a widely used procedure to study the impact of altered gravity on Earth, as observed during spaceflights, allowing us to understand how a long-term physical constraint can condition the mammalian physiology. It is known that mice, placed in classical cages and maintained during 21 days in a centrifuge at $3 G$ gravity level, undergo physiological adaptations due to hypergravity, and/or stress. Indeed, an increase of corticosterone levels has been previously measured in the plasma of 3G-exposed mice. Corticosterone is known to modify neuronal activity during memory processes. Although learning and memory performances cannot be assessed during the centrifugation, literature largely described a large panel of proteins (channels, second messengers, transcription factors, structural proteins) which expressions are modified during memory processing. Thus, we used the Illumina technology to compare the whole hippocampal transcriptome of three groups of C57Bl6/J mice, in order to gain insights into the effects of hypergravity on cerebral functions. Namely, a group of 21 days 3G-centrifuged mice was compared to (1) a group subjected to an acute corticosterone injection, (2) a group receiving a transdermal chronic administration of corticosterone during 21 days, and (3) aged mice because aging could be characterized by a decrease of hippocampus functions and memory impairment. Our results suggest that hypergravity stress induced by corticosterone administration and aging modulate the expression of genes in the hippocampus. However, the modulations of the transcriptome observed in these conditions are not identical. Hypergravity affects per-se the hippocampus transcriptome and probably modifies its activity. Hypergravity induced changes in hippocampal transcriptome were more similar to acute injection than chronic diffusion of corticosterone or aging.

Keywords: aging, chronic stress, acute stress, gravity, hippocampus, transcriptome, Illumina

\section{INTRODUCTION}

Stress is known to modulate memory by affecting the hippocampus functions. As reviewed recently (Kim et al., 2015; Pearson-Leary et al., 2015), norepinephrine and glucocorticoids act on memory via modulations of neuronal functions, neurogenesis, and glial cells. The effects of glucocorticoids depend on their concentration, synthesis, and turn-over. Moreover, as suggested by the high density 
of glucocorticoids receptors, the hippocampus, together with the amygdala, represent one of the main targets of glucocorticoids (Reul and De Kloet, 1985). Indeed, infusions of corticosterone (or its analogs) in the hippocampus affect memory performance in different paradigms (Micheau et al., 1984; Roozendaal and McGaugh, 1997). Glucocorticoids appear to be necessary for memory consolidation, yet while acute post-training injection of low doses enhance performance in aversive and spatial tasks, higher doses or chronic treatment with low doses impair memory and hippocampal functions (McGaugh and Roozendaal, 2002; Marks et al., 2015). However, a very high dose of corticosterone is able to mimic the memory impairment observed in the posttraumatic stress disorder (PTSD; Kaouane et al., 2012), which is characterized by hypermnesia for the core traumatic event associated with a memory deficit for peritraumatic contextual cues.

Besides the typical events leading to stress, an increase of corticosterone levels in plasma samples has been observed in rats (Petrak et al., 2008) and mice (Gueguinou et al., 2012) exposed to conditions of altered gravity.

Life is conditioned by the gravity vector, from conception to adult stages. Adult mammals, during their whole life, need to integrate this force to coordinate the communication between organs and maintain their physiology in a balanced steadystate. The alteration of gravity is a model used to shed light on fundamental processes implicated in environmental adaptation influencing the genomic expression, and it may be helpful to understand how organisms can evolve and adapt to their life on Earth. However, during space flights, astronauts undergo gravity modifications. The most remarkable effects induced by microgravity observed after spaceflights in both humans and rodents are bone decalcification, decrease of musculature, and cardiovascular deconditioning, but they also show spatial disorientation, depressive-like, and cognitive disorders (Porte and Morel, 2012). In space, astronauts as animal models are exposed to several healthy risks, such as secondary radiations (due to high energy protons from solar radiation), modification of light-dark cycle, confinement, and modification of gravity level. In order to isolate the impact of gravity and confinement from the radiation exposures, we used a model consisting of the confinement of mice in a centrifuge, which creates a modification in gravity level.

Using the same protocol, a behavior analysis using a Morris water maze 15 days after exposure to hypergravity (21 days, 3G) suggested that the memory processes could be affected (Bojados and Jamon, 2014). In the same conditions, corticosterone blood levels also revealed that the stress level in these mice was increased in the hours following centrifugation (Gueguinou et al., 2012). The increase of corticosterone levels observed in this study could be ascribed to (1) a long lasting stress induced by the hypergravity and/or (2) an acute stress due to the centrifuge brake.

Since gravity changes induce modifications of genome expression in several tissues (Morel et al., 2014), we hypothesized that hypergravity as well as stress (induced by acute or chronic administration of corticosterone) could affect the genome expression in the hippocampus, with putative effects on memory. In fact, modifications of spatial memory have been previously suggested in rat exposed to hypergravity (Mitani et al., 2004). To assess the relationship between centrifugation and stress effects on hippocampal structure, we performed a transcriptomic analysis of the hippocampus of mice which underwent either centrifugation or chronic and acute corticosterone administration.

Finally, since deleterious effects induced by gravity modifications have been presented as an acceleration of aging (Vernikos and Schneider, 2010), we compared the hypergravity situation with aging effects on the hippocampus transcriptome (Vernikos and Schneider, 2010); moreover, aging is also associated with an increase of plasma corticosterone levels and modifications in hippocampus-dependent processes (Lo et al., 2000; Garrido et al., 2012a,b).

\section{MATERIALS AND METHODS}

\section{Animals, Centrifugation, and Corticosterone Treatments}

Eight week-old C57BL/6J male mice were purchased from Charles River (Les Oncins, 69,210 Saint Germain sur l'Arbesle, France) and housed in standard cages (four mice per cages, $36 \times$ $20 \times 14 \mathrm{~cm})$ under standard conditions $\left(22^{\circ} \mathrm{C}, 55 \%\right.$ humidity, $12 / 12 \mathrm{~h}$ light-dark cycle) with free access to standard food and water. Mice were habituated to animal room for 2 weeks prior to beginning testing.

Mice were divided into different groups described as follows: 24 mice (six cages) were placed in the centrifuge at $3 \mathrm{G}$ for 21 days ( $3 \mathrm{G}$ group $=$ hypergravity); 24 mice were placed in normogravity $(1 \mathrm{G}$ group $=$ confinement $)$ in the centrifuge room and confined in the same gondola as used in the centrifuge. The cages were supplied with enough food and water to allow an uninterrupted 21 days centrifugation/confinement period. This part of the experiment was performed in the animal facility containing the centrifuge (Hôpital de la Timone; Marseille, France; Marc Jamon was responsible for centrifugation).

A group of 10 mice were implanted subcutaneously with Matrix-Driven Delivery (MDD) pellets (Innovative Research of America, Sarasota, FL, USA) containing $10 \mathrm{mg}$ of corticosterone, allowing the constant and continuous delivery of corticosterone during 21 days (CC group). Likewise, a control group of 10 mice were implanted with the placebo pellets during 21 days (PL group), in order to rule out a putative confounding effect of implantation and surgery in the CC group. One mouse treated with placebo died before the end of the protocol. Furthermore, 10 mice (13 weeks old, aged-matched with CC and PL groups on the day of euthanasia) received a single intraperitoneal injection of corticosterone (in 2-hydroxypropyl- $\beta$-cyclodextrin complex; $1.5 \mathrm{mg} / \mathrm{Kg}$; in a volume of $0.1 \mathrm{ml} / 10 \mathrm{~g}$ bodyweight; group AC), $1 \mathrm{~h}$ before euthanasia as described previously (Kaouane et al., 2012).

Finally, a group of 15 mice of 22 month (AGE group) was also included in the study to compare the effect of aging to hypergravity and corticosterone-induced stress.

CC, PL, AC, and AGE mice were housed in the animal facility of our laboratory, in Bordeaux, France. 
All animal groups are summarized in Table 1.

The project has been validated by the French Ministry of Research in accordance with the European Community and French guiding principles (C2EA-50 (Bordeaux) C2EA-14 (Marseille)). The principal investigator is authorized by French authorities to perform animal experiments ( $\mathrm{n}^{\circ}$ C33-01-029).

Mice were euthanized in the same time window (9-11 a.m.) by a lethal dose of pentobarbital, brains were extracted from the skull and blood was collected. Hippocampi were dissected and placed in $2 \mathrm{~mL}$ tubes containing $1 \mathrm{~mL}$ of tri-reagent (TR118, MRC, Cincinatti, OH) and 10-12 ceramic bead (SiLibeads, ZS, 2-2.2 mm diameter, Labomat Essor, Saint-Denis France) and frozen in dry ice. Samples of group $1 G$ and $3 G$ were transported to Bordeaux in dry ice. All samples were prepared for transcriptomic analysis as described below.

\section{Preparation of RNA Samples for Transcriptomic Assays}

After disruption and homogenization of all samples with minilys (Precellys, distributed by Ozyme France, Montigny le Bretonneux) in tri-reagent (Molecular Research Center, Inc., Cincinnati, USA), isolation of the total RNA from each hippocampus was performed following the supplier procedures. RNA integrity and purity were verified by using RNA HighSens Analysis Kit (Experion, BioRad, Marne-la-Coquette, France) and the concentration of RNA was measured with spectrophotometry (NanoDrop Technologies, Wilmington, DE) for each hippocampus. We determined that the total RNA in one hippocampus was not sufficient to be sequenced by Illumina. Thus, the RNAs from three to eight mice were pooled in order to generate three samples for each experimental condition (Supplementary Figure 1). Samples were sent to GATC, the company which verified the quality of the samples and performed the transcriptomic analysis using Genome Sequencer Illumina HiSeq2000* (sequence mode single read $1 \times 50 \mathrm{bp}$ ), and sequences were mapped. The quantities of sequences obtained in each sample were sufficient to perform a statistical analysis (Supplementary Figure 2).

\section{Quantitative Real-Time Polymerase Chain Reaction after Transcription (RT-qPCR)}

Reverse transcription (RT) reaction was carried out using the iScript advanced kit (Bio-Rad). Obtained cDNA were amplified using the primers designed with Quantprime software (Arvidsson et al., 2008). The sequences of primers finally used are indicated as forward primer/reverse primer [accession number], current name of the gene. CATTACCCAGGTATT
GCTGTTCCC/TAGAGCTCCCAGTGTGCTGTAG [NM_0010 33260.1], stox1; CGTTCCATGAATTCGCGGATGTG/TGCT GTAGGAGTATGGGCTGAG [NM_013697.4], ttr; TTCCCA GTGGTGACTGTCCAAG/TCTTCGCCACAAAGGCACCTG [NM_001110227.1], kcnj13; TCTCTGGTGATCAGGATACA GGTG/AGCCGTGGAGAAGATCTGAGAC [NM_022310.2], hspa5; AGAATCCAGGGTGCAGGTATGG/TCTTGGCAGGC CTCACTTTGTTC [NM_144841.3], otx2; TTCACTCTGGGA AATATGCACAGG/GTGGCCACTTGCACATTGTAG [NM_ 008491.1], lcn2; TGGCCTGAATCACTTGGACAGC/ATCA TATTGCCCAGGAGCCTGAAG [NM_008220.4], hbb-b1. The real time qPCR experiments were performed with the SsoADV Univer SYBR Green Supermix (Bio-Rad) in the CFX96 thermocycler (Bio-Rad). The specificity of the amplification products was confirmed by melting curve analysis. All samples were analyzed in duplicates. PCR efficiency was calculated from the slope of the standard curve. Gene expression levels were calculated using the 2-dCt method normalized by reference gene (stox1) that is steadily expressed in transcriptomic analysis and we have verified also by RT-qPCR.

\section{Corticosterone Assays}

Blood was drawn just after the cervical dislocation. After 10 min, samples were centrifuged during $15 \mathrm{~min}$ at $1000 \mathrm{~g}$ and supernatants were collected and stored at $-20^{\circ} \mathrm{C}$ before assays. The quantification of endogenic mouse corticosterone in blood samples was performed using EIA kit DetectX Corticosterone (Arbor Assays, Michigan distributed by Euromedex) following the instructions of the supplier: samples and standards solutions were diluted $(1: 100)$ in the buffer and placed in the plate in duplicates. The reaction buffer containing anticorticosterone antibody was added and after $2 \mathrm{~h}$ of incubation the chemoluminescent subtract was added. The chemoluminescence was measured with the Optima apparatus (BMG Labtech, Champigny sur Marne, France).

\section{Statistical Analysis}

The first steps of transcriptomic data analysis were performed by GATC. To validate the statistical analysis, $p$-values were corrected using the Benjamini and Hochberg procedure controlling false discovery rate (FDR). Supplementary statistical analyses were performed with Graphpad prism software (Graphpad software Inc., La Jolla, CA). Data were expressed as means \pm S.E.M.; $n$ represents the number of tested animals. The samples were compared pair by pair with $t$-test and with one-way ANOVA. The $P<0.05$ were considered as significant and indicated by $\star$ in figures.

TABLE 1 | Design of experimental groups.

\begin{tabular}{|c|c|c|c|c|c|c|}
\hline Group & $3 G$ & $1 G$ & $A C$ & $\mathrm{Cc}$ & PL & AGE \\
\hline Age & & \multicolumn{4}{|c|}{10 weeks at the beginning of the protocol } & 80 weeks \\
\hline Treatment & Centrifuge & None & Corticosterone Intraperitoneal & Corticosterone & Placebo & None \\
\hline
\end{tabular}




\section{Database Queries}

The list of proteins was analyzed using Database for Annotation, Visualization, and Integrated Discovery (DAVID; https://david. ncifcrf.gov), in order to identify the associated pathways and function of the different genes modified in the experimental conditions. The query was made as proposed: sp-pir-keywords for functional categories and biocarta, KEGG pathway, and panther pathway for signaling pathways. Finally, MGI database was used to suggest the putative phenotype outcome of changes induced by hypergravity.

\section{RESULTS}

\section{Corticosterone Levels}

As described previously in mice centrifuged in the same device (Gueguinou et al., 2012), we measured an increase of the plasma level of corticosterone during the $2 \mathrm{~h}$ following a period of 21 days in the centrifuge at $3 \mathrm{G}(59.4 \pm 8 \mathrm{ng} / \mathrm{mL}$ vs. 113 $\pm 11.6 \mathrm{ng} / \mathrm{mL}$ for $1 \mathrm{G}$ and $3 \mathrm{G}$ groups, respectively; $n=24$ for each group; $p=0.0004$ ). We also noticed that in the $3 \mathrm{G}$ group the variability of individual measurements was increased (Figure 1A). We therefore decided to complete the statistical analysis by the modified Thompson tau test to determine the outliers' points. The result remained unchanged $(52.5 \pm 7 \mathrm{ng} / \mathrm{mL}$, $n=22$ vs. $107 \pm 10 \mathrm{ng} / \mathrm{mL}, n=23$ for $1 \mathrm{G}$ and $3 \mathrm{G}$ groups, respectively; $p=0.0001$ ).

To compare the effects of hypergravity on the transcriptome to those observed in stress conditions, we treated mice chronically with corticosterone pellets. The levels of corticosterone in blood of animals treated with chronic corticosterone and placebo were evaluated $(33.6 \pm 7 \mathrm{ng} / \mathrm{mL}, n=9$ vs. $51.3 \pm 8.2 \mathrm{ng} / \mathrm{mL}, n=10$ for PL and CC groups, respectively; $p=0.118$ ), and the $p$-value was ameliorated by the use of the modified Thompson tau test $(28.4 \pm 5.3 \mathrm{ng} / \mathrm{mL}, n=8$ vs. $51.3 \pm 8.2 \mathrm{ng} / \mathrm{mL}, n=10$ for PL and CC groups, respectively; $p=0.042$ ), as reported in Figure 1B.

The acute intraperitoneal injection of corticosterone induced an increase of blood corticosterone concentration close to 10-fold more than in the $3 \mathrm{G}$ group $(1201.8 \pm 232.7 \mathrm{ng} / \mathrm{mL}, n=10$; oneway ANOVA, $p=0.001$ in comparison with all other groups).
Finally, in aged mice corticosterone levels were not significantly affected in comparison with the placebo group used as control younger mice $(33.6 \pm 7 \mathrm{ng} / \mathrm{mL}, n=9$ vs. $52.7 \pm 17.1 \mathrm{ng} / \mathrm{mL}, n=15 ; p=0.193$. After the modified Thompson tau test, values were $28.4 \pm 5.3 \mathrm{ng} / \mathrm{mL}, n=8$ vs. $38.0 \pm 9.3 \mathrm{ng} / \mathrm{mL}, n=14 ; p=0.383$; for PL and AGE groups, respectively, Figure 1C).

\section{Transcriptomic Analysis}

The Illumina analyses revealed the presence of 33,842 different sequences in the transcriptome of the hippocampus. The statistical comparison showed that the expressions of 82 transcripts were affected by hypergravity compared to normogravity, corresponding to 77 identified genes, while 5 sequences were not associated to known genes. In the other conditions, some genes were associated with several sequences; we have mentioned them in Table 2 as repeated sequences. After excluding sequences not associated with gene names and repeated sequences, the expressions of 110 transcripts were modified by acute injection of corticosterone compared to placebo, 102 by chronic administration of corticosterone compared to placebo, and finally 3308 by aging compared to young mice placed in normogravity (Table 2 ).

The global modifications of transcriptome produced by the different experimental conditions were compared and summarized in a Venn diagram in Figure 2. The profile of the hypergravity effect was qualitatively and quantitatively more similar to the effect of the acute injection of corticosterone than to the long lasting delivery of corticosterone.

To map the putative effects of hypergravity, we used the DAVID database. Seventy six genes were analyzed and dispatched in 37 groups. Figure 3 summarized how the genes could be grouped according to their known functions and cellular localization. The detailed DAVID queries are described in Supplementary Table 1.

The statistical comparisons between control and experimental groups were grouped in Supplementary Table 2. In details, the increases of expression levels of eight transcripts and the decreases of the expression of two transcripts were specifically
A

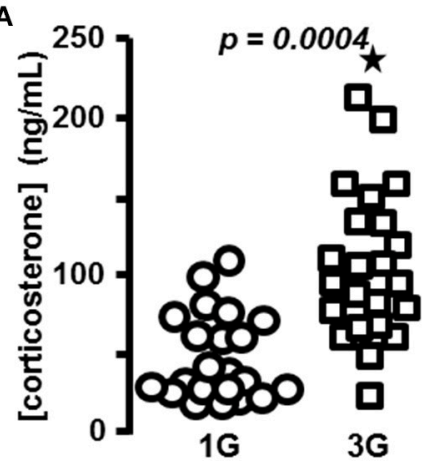

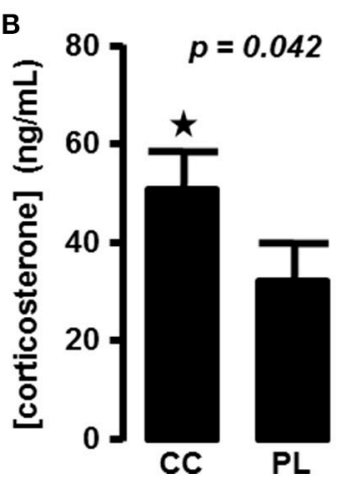

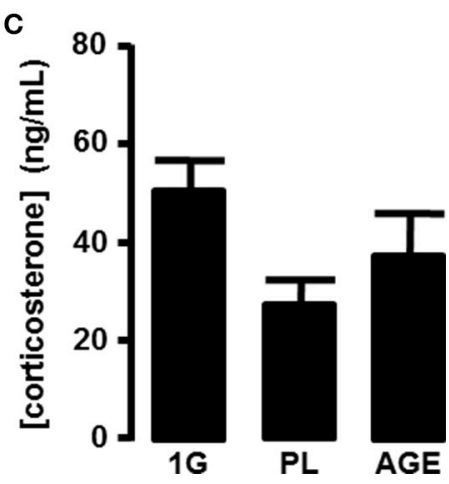

FIGURE 1 | Blood corticosterone concentrations. (A) in 1G- (circle) and 3G- (square) exposed animals; each dot represents the mean of the duplicate measured for each animal. (B) Mean of corticosterone concentration measured in placebo and chronic corticosterone treatment. The results were statistically compared with $t$-test; $\star p<0.05$. (C) Mean of corticosterone concentration measured in placebo, $1 \mathrm{G}$ and aged mice groups. 
TABLE 2 | Number of transcripts affected by experimental conditions.

\begin{tabular}{lcccc}
\hline Group comparison & 3G vs. 1G & AC vs. PL & CC vs. PL & 1G vs. AGE \\
\hline Sequences & 33,842 & 33,842 & 33,842 & 33,842 \\
Fail & 1061 & 994 & 943 & 892 \\
Lowdata & 93 & 93 & 93 & 93 \\
No test & 4049 & 1122 & 1891 & 1959 \\
Seq analyzed & 28,639 & 31,633 & 30,915 & 30,898 \\
P < 0.05 & 82 & 131 & 108 & 4095 \\
Not associated with genes & 5 & 20 & 6 & 592 \\
Repeated sequences & 0 & 1 & 0 & 195 \\
Identified sequences & 77 & 110 & 102 & 3308
\end{tabular}

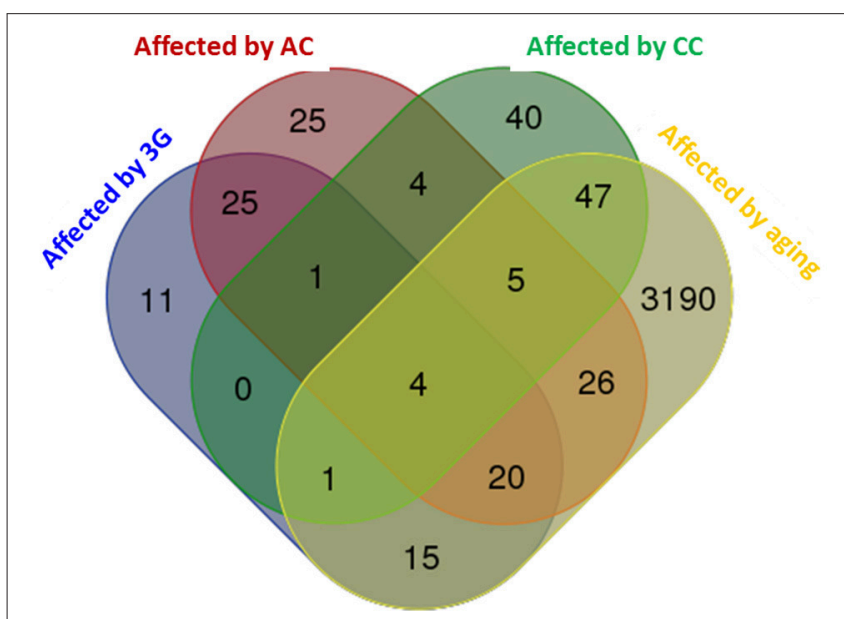

FIGURE 2 | Venn diagram comparing the effects of all experimental conditions on hippocampus transcriptome. The diagram was produced by the software available on http://bioinformatics.psb.ugent.be using the lists of genes statistically affected in each experimental condition. The number of genes affected by the experimental conditions is indicated in each colored subset.

affected by hypergravity only (Table 3 ). The Table 4 summarized the comparison between the modification of transcriptome induced by hypergravity and the other conditions (AC, CC, and AGE). Hypergravity and acute injection of corticosterone similarly affected the expression of 49 transcripts (but for 26 of them, a marked difference is noticeable between PL and $1 \mathrm{G}$ groups), and three transcripts were altered in opposite ways when compared respectively to normogravity and PL controls (Table 5).

The chronic administration of corticosterone and hypergravity affected the expression of four transcripts similarly (but for two of them, a marked difference is noticeable between PL and $1 \mathrm{G}$ groups) and showed opposite effects on the expression of two transcripts compared respectively to normogravity and PL controls (details in Supplementary Table 2).

Hypergravity and aging together affected the expression of 45 transcripts, of which 13 were similarly modified and 32 were affected contrariwise compared to adult mice in normogravity (details in Supplementary Table 2). Hypergravity and the acute injection of corticosterone resulted to be the closest experimental conditions in modulating the hippocampal transcriptome. Table 6 lists the 47 transcripts affected by acute injection of corticosterone but not by hypergravity (but for 15 of them, a marked difference is noticeable between PL and $1 G$ groups).

To compare the putative molecular effects and function of $3 \mathrm{G}$ and other experimental conditions, we have crossed the results of DAVID queries to generate Venn diagrams. The effects are not stackable in any functional category proposed by DAVID. As illustrated in Figure 4, some categories are affected by all experimental conditions in Figures 4A-C, whereas some others are modified by only three (Figures 4D,E) or two (Figure 4F) of them. As expected, the aging group is the most affected by the number of gene and the number of function (Supplementary Table 1).

\section{Verification by RT-qPCR of Some Gene Expression Levels}

The analysis of several gene expression levels was performed by RT-qPCR on the same samples used in the previous set of experiments and compared to the transcriptomic results. As shown by transcriptomic analysis, the expression of Hspa5 was increased only in the $3 \mathrm{G}$ condition (Figure 5A); the expression of Lcn2 was increased in $3 \mathrm{G}$ and CC conditions whereas was decreased in $\mathrm{AC}$ conditions as observed in transcriptomic analysis (Figure 5B). Finally, the Figure 5C, illustrated that the expression of Kcnj13 was increased in AC conditions and was not affected in $\mathrm{CC}$ whereas the effect of $3 \mathrm{G}$ appeared weakly significant (Figure 5C). The explanation of this last effect could be ascribed to the fact that in $30 \%$ of $3 \mathrm{G}$ samples the $\Delta \mathrm{Ct}$ values are similar to the $\Delta \mathrm{Ct}$ values measured in $1 \mathrm{G}$ group. Anyway, the ratio between each experimental condition and its control revealed that the observed changes point in the same direction (Figures 5D,E) compared to transcriptomic analysis, showing converging evidence.

\section{DISCUSSION}

We confirmed that (1) C57BL6 mice exposed for 21 days to hypergravity showed an increase of their corticosterone plasma levels, (2) the previously reported variability of the individual adaptation to gravity modifications was indeed present (Beraneck et al., 2012; Gnyubkin et al., 2015).

It is interesting to compare our results with those obtained in other species, devices, and protocols. In rats, the level of corticosterone could increase during hypergravity exposure and after the stop of centrifugation (Petrak et al., 2008), but also increased or decreased depending on the hypergravity protocol and age of the animals, as shown respectively in (Casey et al., 2012; Abe et al., 2013). Thus, the design of the hypergravity protocol is crucial. For example, a regular "stop and go" during the centrifugation can lead to a habituation that can reduce the stress effects.

Taken together, all these studies indicate that the design of the centrifugation protocol and the animal model could 


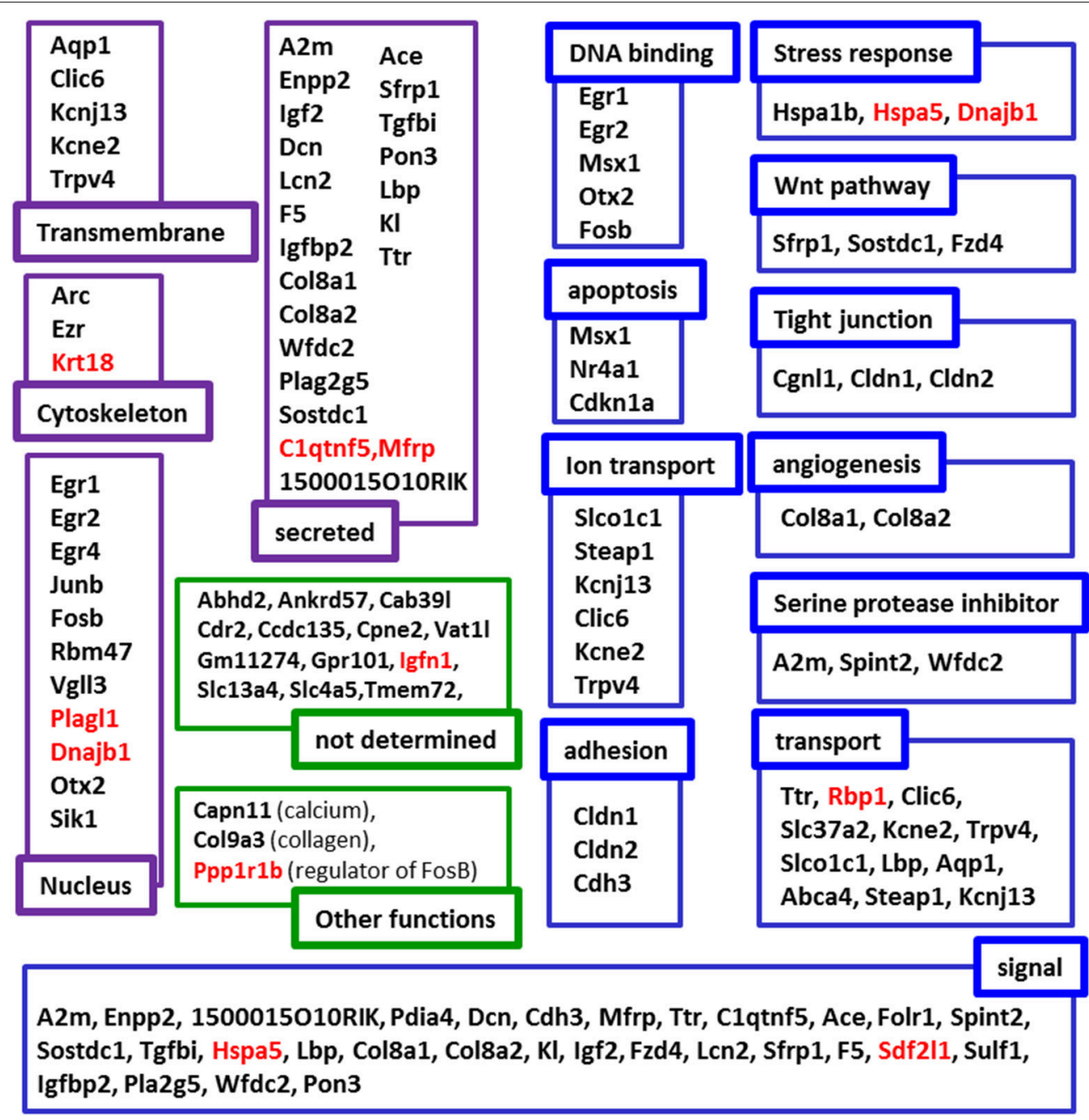

FIGURE 3 | Putative functions and localizations of proteins encoded by genes affected by $\mathbf{3 G}$. The list of genes modified by hypergravity was analyzed using DAVID database and genes listed in DAVID were further grouped according to the localization (purple subsets) and the functions (blue subsets) of their encoding proteins. In green, genes not identified by DAVID were grouped in "not determined" subsets; genes identified in other lists were indicated in "other function subsets" with the function indicated in parenthesis. Genes' names in red indicate those only affected by $3 G$.

TABLE 3 | Transcript expression levels affected only by 3G compared to normogravity (1G) (decreased in italic; all others increased).

\begin{tabular}{|c|c|c|c|c|c|c|}
\hline Gene & Locus & Group 1G & Group 3G & log2(fold_change) & $p$-value & $q$-value \\
\hline Plagl1 & $10: 12810656-12851500$ & 6.098 & 4.172 & -0.5474 & $1.274 E-04$ & 0.04617 \\
\hline $\lg f n 1$ & 1:137878484-137880871 & 0.241 & 0.961 & 1.9973 & 1.137E-04 & 0.04340 \\
\hline Hspa5 & $2: 34627514-34655580$ & 45.661 & 61.084 & 0.4198 & 3.614E-07 & 0.00025 \\
\hline Dnajb1 & 8:86132079-86135915 & 19.787 & 26.955 & 0.4460 & 1.794E-06 & 0.00104 \\
\hline Sfrp1 & 8:24522292-24560100 & 0.993 & 1.637 & 0.7208 & 9.436E-05 & 0.03652 \\
\hline C1qtnf5, Mfrp & 9:43909713-43917327 & 5.721 & 11.043 & 0.9488 & 1.253E-06 & 0.00081 \\
\hline Rbp1 & 9:98325199-98347038 & 12.090 & 18.123 & 0.5840 & 4.914E-05 & 0.02100 \\
\hline Ppp1r1b & 11:98209550-98219164 & 15.030 & 19.941 & 0.4079 & 5.064E-05 & 0.02132 \\
\hline Krt18 & 15:101861304-101862451 & 0.507 & 3.744 & 2.8841 & 6.800E-05 & 0.02704 \\
\hline Sdf2l1 & 16:17130229-17132410 & 10.438 & 17.327 & 0.7311 & 1.432E-07 & 0.00011 \\
\hline
\end{tabular}

The values are expressed as Fragments Per Kilobasepair per Million (FPKM) of the gene in sample with respective p-value and q-value, which is the FDR-adjusted p-value. 
TABLE 4 | Effect of hypergravity on gene expression.

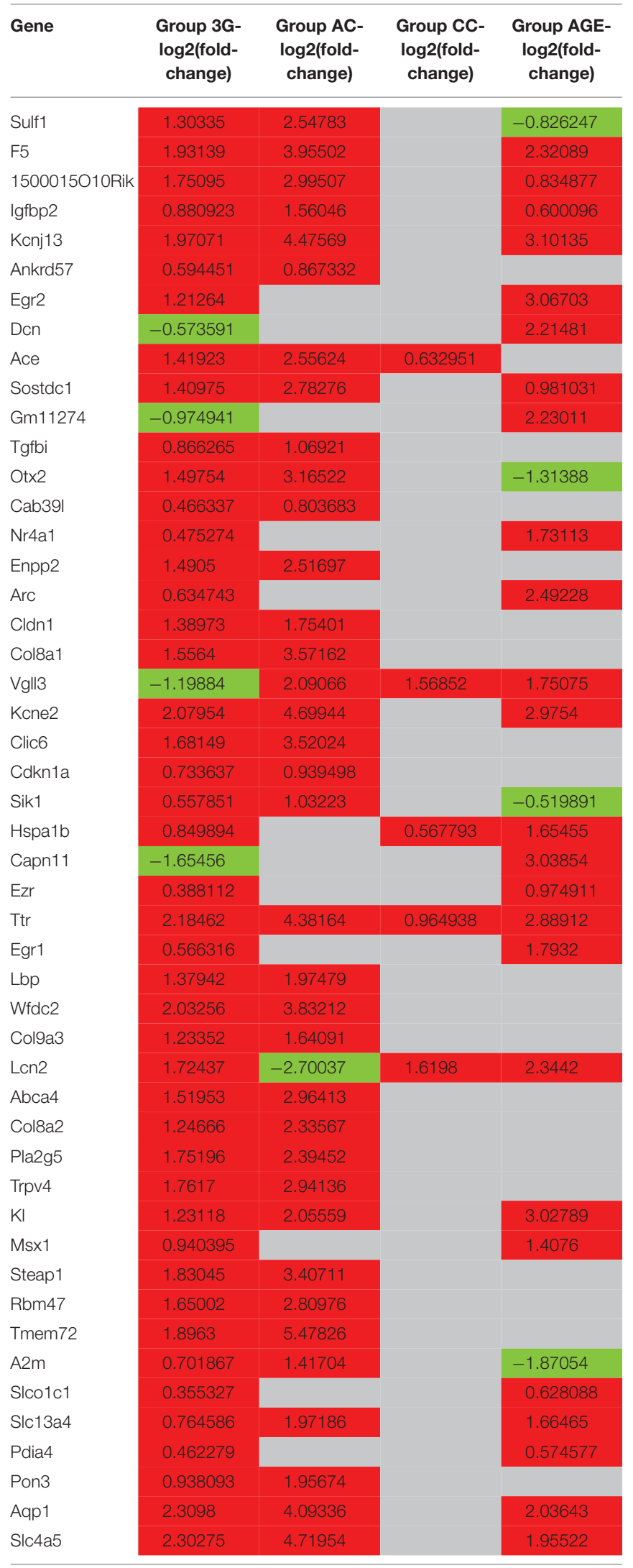

(Continued)
TABLE 4 | Continued

\begin{tabular}{|c|c|c|c|c|}
\hline Gene & $\begin{array}{c}\text { Group 3G- } \\
\text { log2(fold- } \\
\text { change) }\end{array}$ & $\begin{array}{c}\text { Group AC- } \\
\text { log2(fold- } \\
\text { change) }\end{array}$ & $\begin{array}{c}\text { Group CC- } \\
\text { log2(fold- } \\
\text { change) }\end{array}$ & $\begin{array}{c}\text { Group AGE- } \\
\text { log2(fold- } \\
\text { change) }\end{array}$ \\
\hline Egr4 & 0.538811 & & & 2.43387 \\
\hline Folr1 & 1.99678 & 3.64892 & & 1.95393 \\
\hline Cdr2 & 0.604981 & 1.10548 & & -1.43491 \\
\hline $\operatorname{lgf} 2$ & 0.706057 & 1.52015 & & 1.61939 \\
\hline Fosb & 0.818794 & & & 1.39926 \\
\hline Spint2 & 0.626409 & 1.05814 & & \\
\hline Abhd2 & 0.319449 & 0.599141 & & 0.509787 \\
\hline Fzd4 & 0.542651 & 0.784285 & & \\
\hline Cdh3 & 2.78157 & 4.28946 & & \\
\hline Vat1I & 0.649073 & 1.36456 & & -2.60184 \\
\hline Junb & 0.471423 & & & 2.56019 \\
\hline Cpne2 & -0.38987 & 0.661188 & 0.378233 & 0.472237 \\
\hline Ccdc135 & 1.10931 & 2.51124 & & \\
\hline Slc37a2 & 0.917782 & 1.25844 & & \\
\hline Cgnl1 & 0.752135 & 1.08226 & & \\
\hline Cldn2 & 2.13111 & 4.68814 & & 2.30732 \\
\hline Gpr101 & -0.598134 & & & -0.677419 \\
\hline
\end{tabular}

In red box increase of expression, in green box decrease of expression and the gray box indicated that the gene expression is not modified. The values log2(fold-change) between $3 G$ and $1 G$ (Group 3G); $A C$ and $1 G$ (Group AC); CC and $1 G$ (Group CC); AGE and $1 G$ (Group AGE).

influence the stress produced by hypergravity. It would be very interesting to test how centrifugation protocols could influence physiological parameters as plasma concentration of several hormones on different species (mouse and rat) to determine general rules in biological adaptation to gravity levels. Finally, these experiments could also reinforce the theory of the gravity continuum proposed and discussed in the biology and gravity fields (Plaut et al., 2003; VanLoon, 2016). Probably, as suggested by these studies, the effect of hypergravity close to $2 \mathrm{G}$ is the opposite of microgravity, while the effects induced by $3 \mathrm{G}$ acceleration could be different, without following a linear trend. The continuum of gravity should be established independently for each physiological function or tissues.

The absence of handling during the 21 days of centrifugation obliged us to limit the manipulation of mice in the other groups as well; thus the wide range in corticosterone measures and the relatively high corticosterone levels in $1 \mathrm{G}$ controls may reflect a release of corticosterone in response to the stress of handling (Pitman et al., 1988). In this work, we decided to consider the PL group as a control group for AC, despite the fact that more adequate controls would have been mice acutely injected with saline; however, the animal sacrifice was performed $1 \mathrm{~h}$ after the acute injection, time by which its effects on corticosterone levels were unneglectable (Freund et al., 1988). It is noteworthy that all sacrifices were performed in the same time window, not only to limit the bias due to the circadian rhythm of corticosterone synthesis, but also to decrease misinterpretation linked to circadian rhythm of protein synthesis and gene 
TABLE 5 | Transcript expression levels affected by both $3 G$ and AC compared to $1 G$ and placebo, respectively.

\begin{tabular}{|c|c|c|c|c|c|}
\hline Gene & Locus & Group 1G & Group 3G & Group PL & Group AC \\
\hline Sulf1 & 1:12682400-12851259 & 1.98 & 4.888 & 1.024 & 5.989 \\
\hline Igfbp2 & 1:72871044-72899041 & 15.406 & 28.372 & 9.198 & 27.13 \\
\hline Lbp & 2:158132322-158158118 & 2.452 & 6.38 & 1.687 & 6.633 \\
\hline Pla2g5 & 4:138355177-138375157 & 0.345 & 1.163 & 0.202 & 1.064 \\
\hline $\mathrm{Kl}$ & $5: 151755320-151796908$ & 5.741 & 13.477 & 3.428 & 14.25 \\
\hline Pon3 & $6: 5167314-5206224$ & 0.808 & 1.549 & 0.49 & 1.901 \\
\hline Cdr2 & $7: 128100553-128125695$ & 3.29 & 5.005 & 2.772 & 5.964 \\
\hline lgf2 & 7:149836670-149846925 & 18.885 & 30.807 & 10.796 & 30.966 \\
\hline Spint2 & 7:30041283-30067035 & 7.703 & 11.891 & 5.302 & 11.039 \\
\hline Abhd2 & 7:86418109-86510391 & 13.81 & 17.232 & 12.624 & 19.122 \\
\hline Fzd4 & 7:96552850-96561625 & 1.873 & 2.729 & 1.836 & 3.162 \\
\hline Tgfbi & 13:56710929-56740717 & 1.199 & 2.185 & 1.124 & 2.359 \\
\hline Cab39l & 14:60059798-60167840 & 7.41 & 10.238 & 6.317 & 11.027 \\
\hline Enpp2 & 15:54670216-54785330 & 93.005 & 261.333 & 51.59 & 295.292 \\
\hline Cldn1 & 16:26356751-26371926 & 0.692 & 1.814 & 0.714 & 2.409 \\
\hline Cdkn1a & 17:29230693-29237671 & 3.861 & 6.42 & 4.491 & 8.613 \\
\hline Sik1 & 17:31981268-31992685 & 2.661 & 3.917 & 2.023 & 4.138 \\
\hline F5 & 1:166081948-166150560 & 1.042 & 3.977 & 0.3036 & 4.709 \\
\hline Kcnj13 & 1:89223550-89347501 & 0.765 & 2.999 & 0.1747 & 3.887 \\
\hline 1500015010Rik & 1:43787414-43799794 & 4.944 & 16.642 & 1.926 & 15.353 \\
\hline Wfdc2 & 2:164387945-164393983 & 0.706 & 2.887 & 0.196 & 2.797 \\
\hline Slc13a4 & 6:35217813-35258151 & 2.567 & 4.361 & 1.262 & 4.949 \\
\hline Aqp1 & 6:55286159-55298535 & 0.941 & 4.664 & 0.274 & 4.67 \\
\hline Slc4a5 & 6:83187361-83254934 & 0.649 & 3.2 & 0.123 & 3.233 \\
\hline Folr1 & 7:108988596-109017870 & 4.438 & 17.713 & 1.327 & 16.641 \\
\hline Cdh3 & 8:109079141-109079838 & 0.131 & 0.903 & 0.043 & 0.844 \\
\hline Ccdc135 & 8:97579011-97602287 & 2.471 & 5.331 & 1.082 & 6.166 \\
\hline Ace & 11:105829288-105851266 & 3.804 & 10.173 & 1.706 & 10.035 \\
\hline Sostdc1 & 12:37040651-37045032 & 2.486 & 6.606 & 0.946 & 6.513 \\
\hline Otx2 & 14:49277354-49287141 & 1.418 & 4.005 & 0.483 & 4.332 \\
\hline - & 14:76651174-76652137 & 5.640 & 14.079 & 1.432 & 10.791 \\
\hline Col8a1 & 16:57624392-57678659 & 0.553 & 1.626 & 0.181 & 2.149 \\
\hline Kcne2 & 16:92292609-92298528 & 1.715 & 7.248 & 0.234 & 6.082 \\
\hline Clic6 & 16:92498344-92541580 & 2.629 & 8.434 & 0.831 & 9.539 \\
\hline Ttr & 18:20818884-20832827 & 375.259 & 1705.95 & 69.393 & 1446.51 \\
\hline Cldn2 & X:136335278-136345917 & 0.831 & 3.641 & 0.155 & 4.004 \\
\hline Len2 & 2:32240155-32243278 & 0.958 & 3.167 & 2.081 & 0.32 \\
\hline Cpne2 & 8:97057028-97094435 & 18.178 & 13.873 & 9.387 & 14.844 \\
\hline Vgll3 & 16:65828218-65866609 & 1.016 & 0.442 & 0.193 & 0.821 \\
\hline
\end{tabular}

In bold: when groups $1 G$ and PL presented values different of more than two-fold, i.e., confinement effect; in italic: when the effects between $1 G$ and $3 G$ and between PL and AC were in opposite ways; for all other sequences, there was no difference between $1 G$ and $P L$, and both comparisons showed similar increases. The values are expressed as Fragments Per Kilobasepair per Million (FPKM) of the gene in sample. 
TABLE 6 | Transcript expression levels affected by AC but not by $3 G$ and compared to $1 G$ and placebo, respectively (in bold: when groups $1 G$ and PL presented values different of more than two-fold).

\begin{tabular}{|c|c|c|c|c|c|}
\hline Gene & Locus & Group PL & Group AC & Group 1G & Group 3G \\
\hline Prelp & 1:135806851-135817995 & 6.119 & 10.092 & 8.991 & 11.076 \\
\hline Rgs16 & 1:155587388-155592662 & 2.468 & 8.272 & 2.594 & 3.453 \\
\hline Plcb4 & $2: 135485156-135840371$ & 4.181 & 8.883 & 4.704 & 4.926 \\
\hline Bmp7 & 2:172693519-172765977 & 1.034 & 2.264 & 1.743 & 2.322 \\
\hline Sox18 & $2: 181404542-181406350$ & 2.634 & 1.088 & 3.305 & 3.348 \\
\hline Sgms2 & 3:131033242-131153082 & 0.501 & 1.128 & 0.690 & 1.091 \\
\hline Txnip & 3:96361859-96365785 & 6.449 & 15.570 & 6.819 & 9.094 \\
\hline Rims3 & 4:120527441-120569406 & 8.236 & 13.792 & 8.760 & 9.828 \\
\hline Id3 & 4:135699645-135701474 & 18.669 & 10.784 & 18.856 & 21.987 \\
\hline Alpl & 4:137297663-137352249 & 1.573 & 3.168 & 2.559 & 3.427 \\
\hline Errfi1 & 4:150229180-150243052 & 11.745 & 18.439 & 12.633 & 13.599 \\
\hline Hes5 & 4:154335009-154336494 & 3.570 & 1.047 & 4.734 & 3.688 \\
\hline Cit & 5:116357249-116459005 & 6.297 & 11.750 & 7.865 & 9.303 \\
\hline AC113316.1 & 5:147043206-147114511 & 18.642 & 291.688 & 32.813 & 34.458 \\
\hline Apold1 & 6:134933638-134936893 & 0.947 & 2.796 & 1.037 & 1.597 \\
\hline Mdfic & 6:15671340-15752163 & 0.705 & 2.036 & 1.041 & 1.737 \\
\hline Hbb-b1 & 7:110975050-110982005 & 355.809 & 546.092 & 462.061 & 501.292 \\
\hline Syt9 & $7: 114514498-114692169$ & 1.253 & 2.976 & 1.742 & 1.506 \\
\hline Zfp36 & 7:29161807-29164279 & 1.273 & 3.202 & 1.869 & 2.431 \\
\hline Plekhf1 & 7:39005604-39012997 & 1.458 & 3.225 & 1.718 & 1.885 \\
\hline Tnnt1 & $7: 4456181-4466249$ & 0.337 & 3.947 & 0.345 & 0.443 \\
\hline Slc17a6 & 7:58877006-58926498 & 3.873 & 8.414 & 3.278 & 3.980 \\
\hline Lars2 & 9:123276062-123371876 & 13.944 & 115.222 & 14.733 & 14.913 \\
\hline Amotl1 & 9:14346410-14447921 & 2.982 & 6.149 & 3.287 & 3.750 \\
\hline Slc37a2 & 9:37035195-37063010 & 0.495 & 1.183 & 0.624 & 1.178 \\
\hline Zic1 & 9:91252845-91260745 & 1.643 & 5.271 & 2.526 & 3.483 \\
\hline D10Bwg1379e & 10:18299938-18463830 & 1.924 & 0.000 & 2.127 & 2.047 \\
\hline Perp & $10: 18564896-18576876$ & 1.122 & 2.622 & 1.666 & 2.276 \\
\hline Sgk1 & $10: 21601862-21719710$ & 17.961 & 44.267 & 18.984 & 25.136 \\
\hline Ddit4 & $10: 59412417-59414734$ & 22.596 & 35.464 & 24.492 & 27.538 \\
\hline Arl4d & $11: 101526844-101529145$ & 5.293 & 10.395 & 6.036 & 7.725 \\
\hline Adra1b & $11: 43588132-43649883$ & 0.695 & 1.875 & 0.781 & 0.952 \\
\hline Ramp3 & $11: 6558299-6577482$ & 1.685 & 6.132 & 1.948 & 2.485 \\
\hline Rpl23a & 11:77990411-77997079 & 9.030 & 2.244 & 8.150 & 8.976 \\
\hline Coch & 12:52694347-52706789 & 1.798 & 4.422 & 2.338 & 3.326 \\
\hline Nfkbia & 12:56590395-56593615 & 8.681 & 21.278 & 9.183 & 11.524 \\
\hline Abhd12b & $12: 71255075-71285422$ & 0.092 & 1.096 & 0.132 & 0.110 \\
\hline Gadd45g & 13:51942029-51943872 & 11.307 & 19.046 & 11.666 & 14.819 \\
\hline Slitrk6 & 14:111147307-111154449 & 0.114 & 0.589 & 0.116 & 0.157 \\
\hline Slc39a4 & $15: 76446259-76447453$ & 0.238 & 1.038 & 0.439 & 0.884 \\
\hline Apol7e & $15: 77532443-77532675$ & 14.815 & 0.000 & 13.428 & 21.768 \\
\hline Zc3h7a & $16: 11136694-11176449$ & 18.019 & 66.577 & 16.310 & 16.097 \\
\hline Dusp1 & 17:26642533-26645639 & 6.156 & 10.271 & 7.292 & 9.745 \\
\hline AY036118 & 17:39981973-39985775 & 78.210 & 212.687 & 72.855 & 73.357 \\
\hline Six3 & $17: 86001750-86025499$ & 0.154 & 1.102 & 0.274 & 0.628 \\
\hline Tcf712 & 19:55816309-56008146 & 1.157 & 8.807 & 1.468 & 2.675 \\
\hline Htr2c & X:143396975-143631821 & 6.342 & 12.437 & 8.440 & 9.408 \\
\hline
\end{tabular}


TABLE 6 | Continued

\begin{tabular}{|c|c|c|c|c|c|}
\hline Gene & Locus & Group PL & Group AC & Group 1G & Group 3G \\
\hline Fmod & 1:135933969-135944800 & 1.600 & 3.299 & 3.373 & 3.279 \\
\hline Ptgds & 2:25318620-25321886 & 0.219 & 0.935 & 0.503 & 0.281 \\
\hline S100a8 & 3:90473003-90473954 & 7.764 & 2.042 & 1.499 & 1.563 \\
\hline S100a9 & 3:90496559-90499221 & 8.422 & 2.628 & 2.099 & 1.431 \\
\hline Wdr86 & 5:24216845-24236452 & 0.240 & 3.018 & 0.985 & 2.856 \\
\hline Narg2 & 9:69245774-69280992 & 0.091 & 0.490 & 0.304 & 0.482 \\
\hline Pmch & 10:87553815-87555214 & 0.373 & 2.791 & 0.155 & 0.105 \\
\hline Wfikkn2 & 11:94097301-94104025 & 0.181 & 0.651 & 0.436 & 0.869 \\
\hline Dio3 & 12:111517039-111519293 & 0.689 & 1.699 & 2.572 & 1.545 \\
\hline 4930427A07Rik & 12:114394889-114403682 & 1.909 & 0.244 & 0.292 & 0.310 \\
\hline
\end{tabular}

The values are expressed as Fragments Per Kilobasepair per Million (FPKM) of the gene in sample.

regulation implicated in memory processes (Eckel-Mahan, 2012).

The chronic treatment with corticosterone increased the level of plasma corticosterone ( $p=0.042$, after the Thompson-test revealing one outlier for 19 mice in both groups), yet in a lesser extent than expected. As reported recently, in order to reach a 1.8- to 2-fold increase of the blood corticosterone concentration in mice after 21 days, a dose of $40 \mathrm{mg} / \mathrm{Kg} /$ day would be required (Ali et al., 2015; Weng et al., 2016). In our experiment, the designed pellet delivery was close to $20 \mathrm{mg} / \mathrm{Kg} /$ day and the increase of the measured plasma corticosterone concentration was 1.5 -fold compared to $\mathrm{PL}$ group. Since drug delivery problems can be excluded, this level of blood corticosterone can be due to different turn-over mechanisms.

Interestingly, by comparison with placebo-treated animals, we also observed a slight increase of the corticosterone concentration in group $1 \mathrm{G}$ ( $p=0.052$, $t$-test's comparison) close to the ones observed in aging and chronically-treated mice. This result suggests that containment alone can be sufficient to induce a rise in corticosterone levels. Future experiments should clarify if this increase can impact the memory performance by itself (Salehi et al., 2010).

Before our study, several studies reported that aging as chronic stress affect similarly hippocampus function as learning and memory (Tronche et al., 2010; Bonhomme et al., 2014; Wang et al., 2016), then we hypothesized that the modifications of hippocampus transcriptome induced by hypergravity should be similar to those observed in aged mice and/or mice treated with corticosterone.

The hippocampus transcriptome is modified in each experimental condition. Our results show that there is no overlap between experimental conditions but 61,38 , and $5 \%$ of transcripts modified by hypergravity were respectively modified by $\mathrm{AC}$, aging, and $\mathrm{CC}$ in the same way; whereas 14, 4, and
$<3 \%$ of transcripts modified by hypergravity were respectively modified by aging, AC and CC in the opposite way.

A global analysis of the transcriptome can give a snapshot of the hippocampus status, thereby revealing possible modifications of its functions induced by hypergravity, corticosterone (acute i.p. and long lasting s.c. delivery), and aging. In order to validate our experimental procedure-pooling RNAs from different mice in one sample used in transcriptomic - and to test the biological variability, some gene expressions were analyzed by RT-qPCR.

The data obtained confirmed the effects observed in transcriptomic arrays, suggesting that the experimental design (pooling samples in experimental triplicates) is not able to induce massive bias (Auer and Doerge, 2010; Rajkumar et al., 2015). These data also underlined the effects of hypergravity by increasing the dispersion of individual scores as shown with the corticosterone measurements.

It appears from our result that a very large part of the hypergravity effects on hippocampal transcripts (summarized in Figure 2) is reproducible by an acute injection of corticosterone used to replicate the symptomatology of PTSD (Kaouane et al., 2012). The most probable event comparable to acute stress in our protocol is the stop of the centrifuge. Consequently, we suggest that the stop of the centrifuge is perceived by animals as an acute stress that could induce cognitive disorders close to PTSD. Further experiments should be performed to analyze the memory performance once normogravity is reestablished, using behavioral experiments, such as fear conditioning. Moreover, in order to decrease the effect of rapid gravity modifications as well as to better compare the effects of the gravity in rodents to those seen in humans, animals could be trained to several acceleration training phases or modulation of velocity in both "lift-off" and "landing" phases, etc... Indeed, studies on humans differ largely from the ones using rodents: first, astronauts undergo sustained training before being submitted to space flight; second and most importantly, since humans beings are conscious, they can prepare 

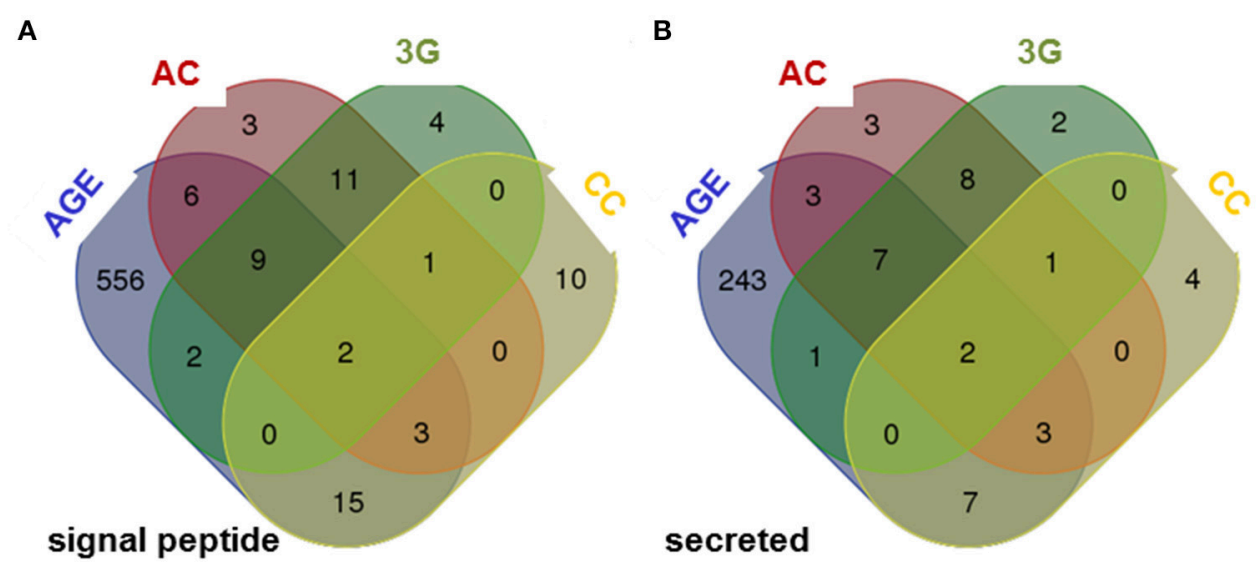

C

D
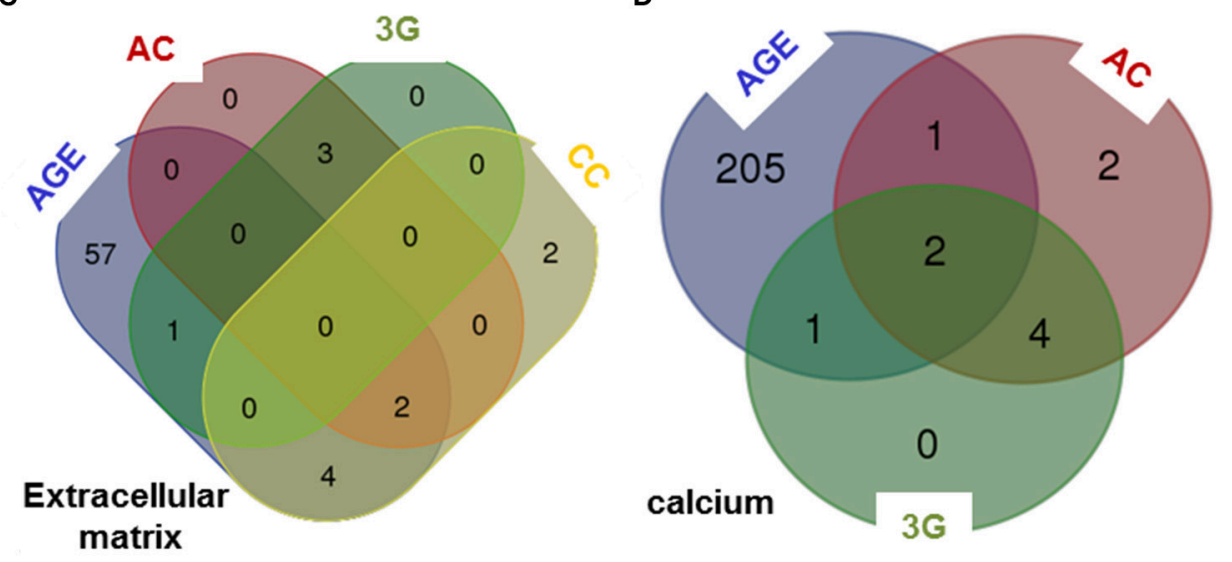

E

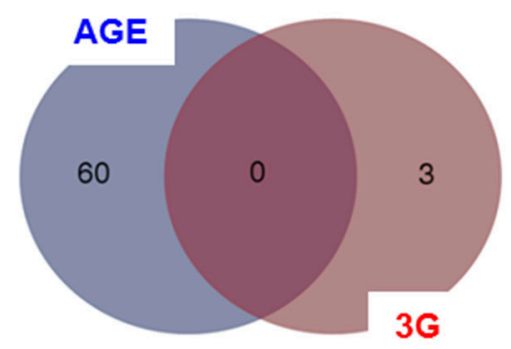

F

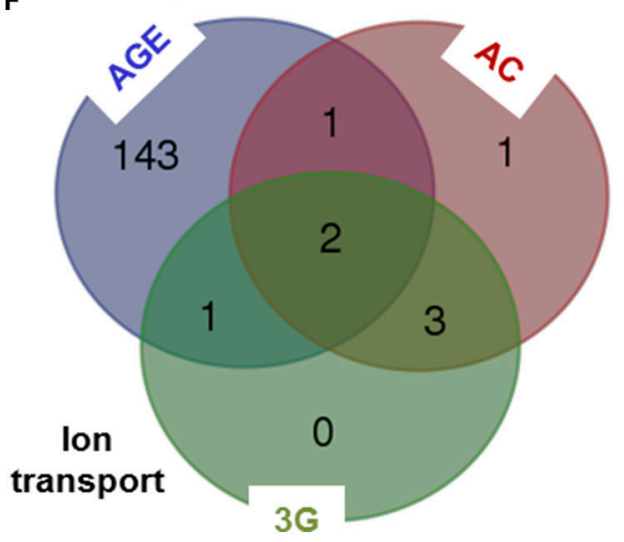

FIGURE 4 | Venn diagrams comparing the queries of DAVID database. The lists of genes modified by all experimental conditions were analyzed using DAVID database and Venn diagrams were created considering six categories of genes encoding: (A) signal peptide, (B) secreted proteins, (C) proteins of the extracellular matrix, (D) proteins implicated in calcium-dependent mechanisms, (E) proteins implicated in Wnt pathway and (F) proteins implicated in ion transport.

themselves to the changes of gravity during the mission (i.e., since they know when and why the gravity changes, thus the situation is less stressful).

Surprisingly, the long lasting subcutaneous diffusion of corticosterone used to mimic a chronic stress is the situation that mostly differs from hypergravity, moreover, there only 14 genes affected by both acute and chronic corticosterone treatments. These treatments were used to mimic stress effects and several studies reported the effects of the acute and chronic stresses modified differently the hippocampus transcriptome (Li et al., 2013; Stankiewicz et al., 2015). Furthermore, the nature of the stressor is also crucial (Porter et al., 2012; Li et al., 2013; Suri et al., 2014; Stankiewicz et al., 2015). Similarly to stress, modifications of living conditions, as well as long-term mild or intense exercise, can modulate the hippocampus transcriptome (Inoue et al., 2015). In our case, the effect of the stop of the centrifuge create 

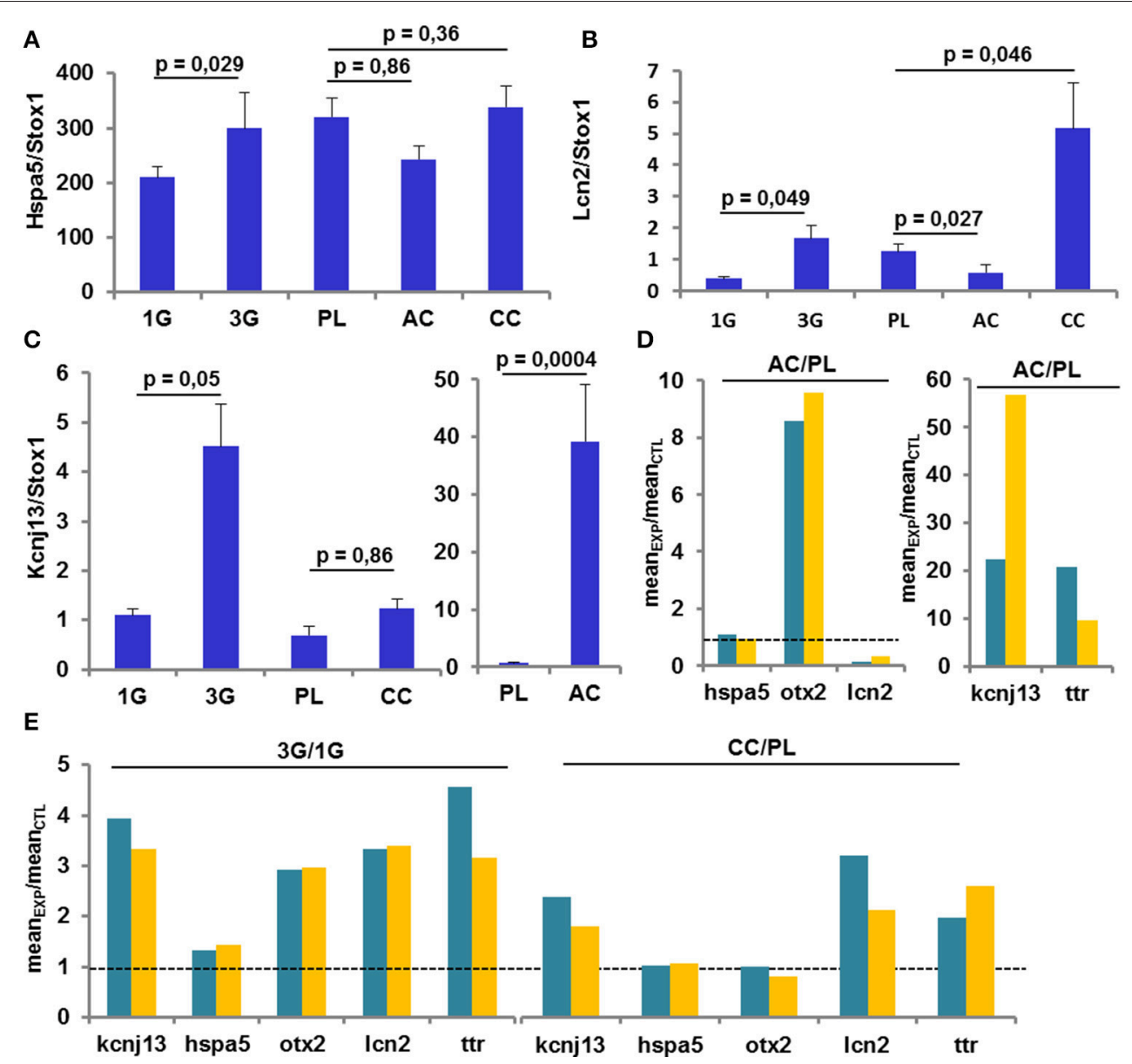

FIGURE 5 | Gene Expression revealed by RT-qPCR. (A-C) Mean \pm sem of gene expression level quantified after RT-q-PCR in all conditions. The $p$-values indicated were obtained by Student's t-test analysis. (D-E) comparison of the ratio AC/PL, CC/PL, and 3G/1G obtained with transcriptomic (green) and RT-qPCR (orange) analysis.

a higher increase of plasma corticosterone compared to the one observed following chronic corticosterone treatment, and reveals a similar modification of the hippocampus transcriptome to the one observed after an acute injection of corticosterone.

Aging is characterized by a substantial modification of the hippocampus transcriptome (close to $10 \%$ of the sequences are affected). This result is probably due to an important dispersion of individual physiological status/history but also to the absence of selection of the mice based on learning and memory performances, for example. Moreover, the number of gene affected by aging depends also on the age of the mice (Stilling et al., 2014). Finally, the lists of genes affected by both aging and corticosterone treatments contain only 55-57 genes, largely different from the hypergravity. These observations underscore that aging as other experimental conditions integrate multiple signals and their complex marks; a transduction pathway can be affected in one or more different steps. Ultimately, it is possible to implicate several identical pathways affected in all conditions as revealed by the results of DAVID queries.

The results obtained in the transcriptome analysis should be evaluated remembering that the hippocampus contains several cell types as neurons, glial cells but also endothelial cells and pericytes constituting blood vessels. A recent study showed that the choroid plexus could be affected by hypergravity and indicated that Ttr, Igf2, Igfbp2, Prlr, Enpp2, Sostdc1, 1500015O10RIK (Ecrg4), Kl, Clic6, Kcne2, F5, Slc4a5, and Aqp1 were more highly expressed in the choroid plexus compared to the brain parenchyma (Stankiewicz et al., 2015). Similarly, in our analysis, we found that the transcription levels of these genes were affected by hypergravity. We cannot totally exclude a bias due to the dissection step. Nevertheless, the effect of gravity modifications on the choroid plexus should be more investigated, because blood and cerebrospinal fluid pressures are both sensitive to hypergravity (Iwasaki et al., 2012).

Globally, the query of MGI database indicated that all affected genes are expressed in nervous system and consequently all biological processes could be affected [Supplementary Figure 3; response to stimulus (concerning 46 genes affected by hypergravity), signaling (28 genes), development (30 genes), immunity (15 genes), localization (29 genes), component organization (29 genes), homeostasis (11 genes), cell differentiation (28 genes), proliferation (17 
genes) and death (15 genes), protein metabolic process (26 genes), nucleic acid templated transcription (20 genes), lipid metabolism (9 genes), and carbohydrate derivative metabolism (6 genes)]. Furthermore, this database also indicated the cell localization (summarized in Figure 6) and the phenotypic modifications revealed in transgenic mice. Thus this query indicated that memory processes could be modified via the increases of expression of Arc, Fosb, Egr1, Kl, and Ppp1r1b and the blood brain barrier and/or the functions and morphology of cerebrovascular sphere could be affected via the modification of gene expressions of Abhd2, Ace, Aqp1, Enpp2, Fzd4, Kl, Nr4a1, Slc4a5, Trpv4, F5, Hspa5, and C1qtnf5, Mfrp. Surprisingly, only 1500015O10Rik (Ecrg4) is implicated in the control of corticosterone production (Tadross et al., 2010) and produced by choroid plexus. Moreover, the query of DAVID database indicated that genes affected by hypergravity encode for proteins implicated in several functions. Probably, the most important common effects of hypergravity and acute injection of corticosterone concerned signaling pathways affecting nucleus functions and secreted proteins as compounds of extracellular matrix and cellular interactions as modulation of tight junctions. However, the cellular metabolism does not seem to be deeply disturbed, as observed in other studies concerning different organs in a pregnant rat model (Casey et al., 2012, 2015). The effects of hypergravity on hippocampal transcripts are not solely overlapped to acute stress, in fact 10 transcripts were per-se modified by hypergravity only. The transcriptomic approach could be used to determine targets potentially affected by environmental modifications (Huttenrauch et al., 2016).

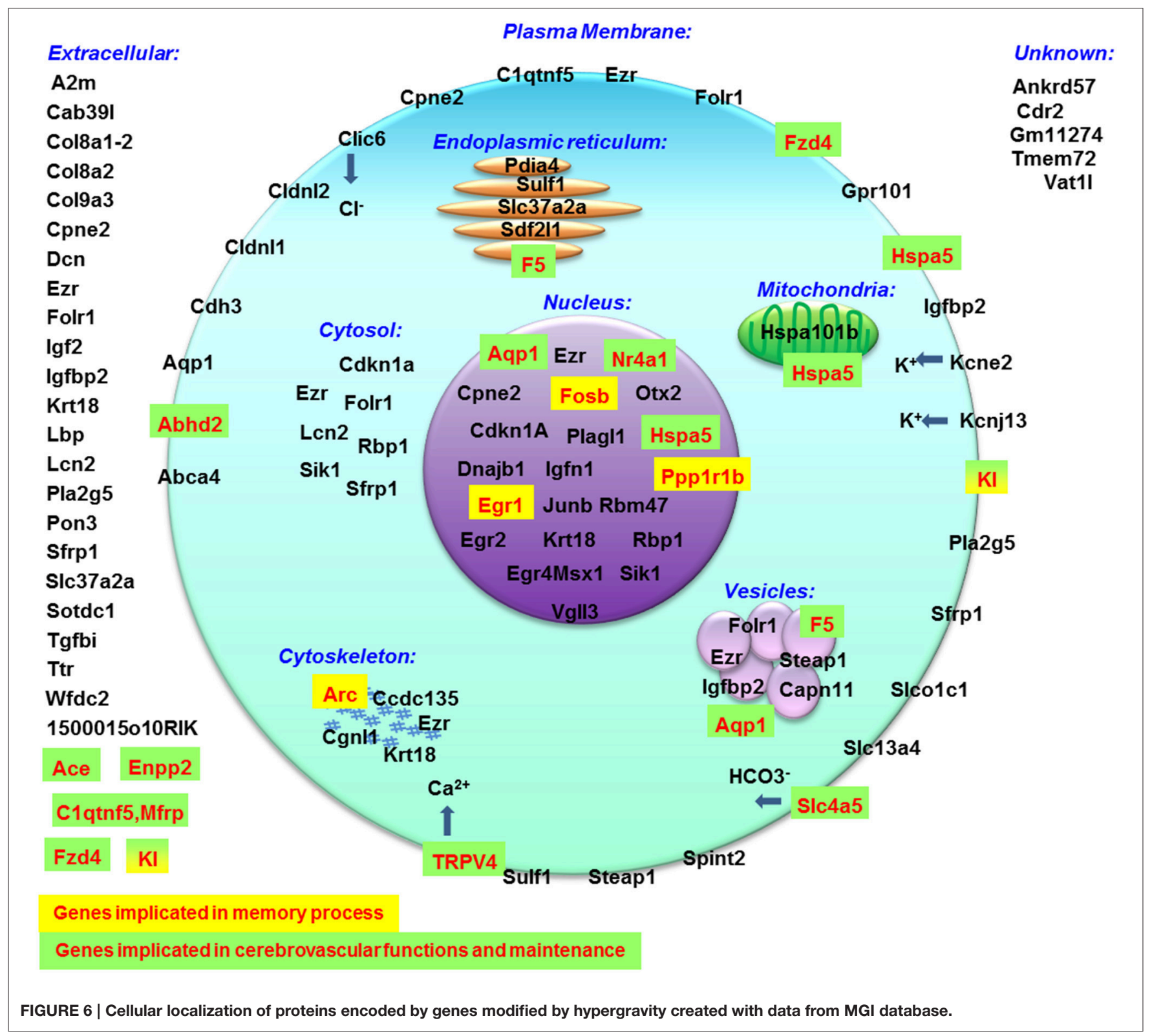


Hypergravity modulate the expression of genes implicated in neuronal differentiation and migration via Plagl1 expression (Adnani et al., 2015). According to DAVID database, the hypergravity can alter learning and memory via the modulation of ppp1r1b, Dnajb1, Rbp1, and Hspa5 genes encoding proteins involved in the regulation of molecular pathways of memory and linked to neurodegenerative disorders (Leil et al., 2003; Ignacak et al., 2009; Heyser et al., 2013; Witt, 2013; Seo et al., 2014; Udan-Johns et al., 2014). The role of CTRP5 encoded by C1qtnf5-Mfrp gene is not described in the brain but it is associated with macular degeneration (Hayward et al., 2003) and lipid oxidation (Yang and Lee, 2014). If the functions of Igfn1 and Krt18 are unknown in neurons, their function in smooth muscle cells (Baker et al., 2010) and implication in intracerebral arteriovenous malformations (Sasahara et al., 2007) indicate that hypergravity could act on pericytes to modify the cerebrovascular function and hippocampus perfusion. Similarly, Sdf2l1, an endoplasmic reticulum stress-inducible gene (Fukuda et al., 2001) is implicated in the folding of proteins (Tiwari et al., 2013) but the function of the encoded proteins in brain cells (neurons, glia, and vessels) remains largely unknown. Finally, sFRP1, encoded by sfrp1 gene, has been found upregulated by hypergravity. It has been shown that the intracerebral injection of this protein antagonized Wnt, resulting in inhibition of bassoon activation (Tabatadze et al., 2014) and the blockade of the CamKII $\alpha$ phosphorylation, decreasing the fear memory acquisition, and consolidation performances (Xu et al., 2015). Thus this last result can suggest that memory could be altered by hypergravity making essential the study of fear conditioning memory in hypergravity models.

In conclusion, even if it is not completely possible to segregate the effects of stress and hypergravity in this model, the transcriptomic analysis indicated that the expression of genes encoding proteins implicated in excitability, cellular interactions, migration, protein synthesis, and cell death, was modified after $3 \mathrm{G}$ exposure. An effect on memory thus cannot be excluded since memory requires a coordinated regulation of many known and unknown proteins (Jarome and Helmstetter, 2014). It is also known that stress affects deeply the cerebrovascular network (Scheuer et al., 2007; Longden et al., 2014). Therefore, a modulation of the vascular network, due to hypergravity,

\section{REFERENCES}

Abe, C., Ueta, Y., and Morita, H. (2013). Exposure to hypergravity during the preweaning but not postweaning period reduces vestibularrelated stress responses in rats. J. Appl. Physiol. 115, 1082-1087. doi: 10.1152/japplphysiol.00285.2013

Adnani, L., Langevin, L. M., Gautier, E., Dixit, R., Parsons, K., Li, S., et al. (2015). $\mathrm{Zacl}$ regulates the differentiation and migration of neocortical neurons via Pac1. J. Neurosci. 35, 13430-13447. doi: 10.1523/JNEUROSCI.0777-15.2015

Ali, S. H., Madhana, R. M., K, V. A., Kasala, E. R., Bodduluru, L. N., Pitta, S., et al. (2015). Resveratrol ameliorates depressive-like behavior in repeated corticosterone-induced depression in mice. Steroids 101, 37-42. doi: 10.1016/j.steroids.2015.05.010

Arvidsson, S., Kwasniewski, M., Riano-Pachon, D. M., and Mueller-Roeber, B. (2008). QuantPrime-a flexible tool for reliable high-throughput primer design should not be totally excluded and could act on brain functions especially in animal models without training as in astronauts (cognitively, emotionally and physically). Considering that 10 genes were modified specifically after $3 G$ exposure, it appears that hypergravity alone modulates the hippocampal activity. We can thus suggest that both the neurogenesis and angiogenesis would be impaired (decrease of plagl1), whereas neuroprotection against hypoxia effects would be ameliorated (increase of rbp1 and dnajb1). Moreover, the increases of expression of factors regulating protein folding (sdf2l1, hspa5) and NMDAdependent signals (ppplr1b) most probably affect the neuronal architecture. Finally, our results could also be compared to other studies using the same approach to understand how the hippocampus transcriptome was adapted to environmental conditions (Huttenrauch et al., 2016).

\section{AUTHOR CONTRIBUTIONS}

The project was initiated by YP continued by AP under supervision of JM. YP and JM prepared samples; AP and JM analyzed the data and JM wrote the manuscript. All authors approved the manuscript.

\section{FUNDING}

The study was supported by grants from Centre National des Etudes Spatiales (CNES; grants $\mathrm{n}^{\circ}$ 007088, 007636) and Agence Nationale pour la Recherche (AdapHyG n ${ }^{\circ}$ ANR-09-BLAN0148). YP was granted by ANR and AP's doctoral fellowship was granted by CNES and Region Aquitaine.

\section{ACKNOWLEDGMENTS}

We thank Marc Jamon and Mickael Bojados for mouse centrifugation, Dr. Anne Prévot for her help in proof reading, and Jean-Luc Dalous for Venn diagrams and DAVID queries.

\section{SUPPLEMENTARY MATERIAL}

The Supplementary Material for this article can be found online at: http://journal.frontiersin.org/article/10.3389/fnmol. 2016.00153/full\#supplementary-material

for quantitative PCR. BMC Bioinformatics 9:465. doi: 10.1186/1471-21059-465

Auer, P. L., and Doerge, R. W. (2010). Statistical design and analysis of RNA sequencing data. Genetics 185, 405-416. doi: 10.1534/genetics.110.114983

Baker, J., Riley, G., Romero, M. R., Haynes, A. R., Hilton, H., Simon, M., et al. (2010). Identification of a Z-band associated protein complex involving KY, FLNC and IGFN1. Exp. Cell Res. 316, 1856-1870. doi: 10.1016/j.yexcr.2010.02.027

Beraneck, M., Bojados, M., Le Seac'h, A., Jamon, M., and Vidal, P. P. (2012). Ontogeny of mouse vestibulo-ocular reflex following genetic or environmental alteration of gravity sensing. PLoS ONE 7:e40414. doi: 10.1371/journal.pone.0040414

Bojados, M., and Jamon, M. (2014). The long-term consequences of the exposure to increasing gravity levels on the muscular, vestibular and cognitive functions in adult mice. Behav. Brain Res. 264, 64-73. doi: 10.1016/j.bbr.2014.01.018 
Bonhomme, D., Pallet, V., Dominguez, G., Servant, L., Henkous, N., Lafenetre, P., et al. (2014). Retinoic acid modulates intrahippocampal levels of corticosterone in middle-aged mice: consequences on hippocampal plasticity and contextual memory. Front. Aging Neurosci. 6:6. doi: 10.3389/fnagi.2014.00006

Casey, T., Patel, O. V., and Plaut, K. (2015). Transcriptomes reveal alterations in gravity impact circadian clocks and activate mechanotransduction pathways with adaptation through epigenetic change. Physiol. Genomics 47, 113-128. doi: 10.1152/physiolgenomics.00117.2014

Casey, T., Zakrzewska, E. I., Maple, R. L., Lintault, L., Wade, C. E., Baer, L. A., et al. (2012). Hypergravity disruption of homeorhetic adaptations to lactation in rat dams include changes in circadian clocks. Biol. Open 1, 570-581. doi: 10.1242/bio. 2012687

Eckel-Mahan, K. L. (2012). Circadian oscillations within the hippocampus support memory formation and persistence. Front. Mol. Neurosci. 5:46. doi: 10.3389/fnmol.2012.00046

Freund, R. K., Martin, B. J., Jungschaffer, D. A., Ullman, E. A., and Collins, A. C. (1988). Genetic differences in plasma corticosterone levels in response to nicotine injection. Pharmacol. Biochem. Behav. 30, 1059-1064. doi: 10.1016/0091-3057(88)90139-6

Fukuda, S., Sumii, M., Masuda, Y., Takahashi, M., Koike, N., Teishima, J., et al. (2001). Murine and human SDF2L1 is an endoplasmic reticulum stressinducible gene and encodes a new member of the Pmt/rt protein family. Biochem. Biophys. Res. Commun. 280, 407-414. doi: 10.1006/bbrc.2000.4111

Garrido, P., De Blas, M., Del Arco, A., Segovia, G., and Mora, F. (2012a). Aging increases basal but not stress-induced levels of corticosterone in the brain of the awake rat. Neurobiol. Aging 33, 375-382. doi: 10.1016/j.neurobiolaging.2010.02.015

Garrido, P., De Blas, M., Gine, E., Santos, A., and Mora, F. (2012b). Aging impairs the control of prefrontal cortex on the release of corticosterone in response to stress and on memory consolidation. Neurobiol. Aging 33, 827.e1-827.e9. doi: 10.1016/j.neurobiolaging.2011.06.011

Gnyubkin, V., Guignandon, A., Laroche, N., Vanden-Bossche, A., Normand, M., Lafage-Proust, M. H., et al. (2015). Effects of chronic hypergravity: from adaptive to deleterious responses in growing mouse skeleton. J. Appl. Physiol. 119, 908-917. doi: 10.1152/japplphysiol.00364.2015

Gueguinou, N., Bojados, M., Jamon, M., Derradji, H., Baatout, S., Tschirhart, E., et al. (2012). Stress response and humoral immune system alterations related to chronic hypergravity in mice. Psychoneuroendocrinology 37, 137-147. doi: 10.1016/j.psyneuen.2011.05.015

Hayward, C., Shu, X., Cideciyan, A. V., Lennon, A., Barran, P., Zareparsi, S., et al. (2003). Mutation in a short-chain collagen gene, CTRP5, results in extracellular deposit formation in late-onset retinal degeneration: a genetic model for age-related macular degeneration. Hum. Mol. Genet. 12, 2657-2667. doi: $10.1093 / \mathrm{hmg} / \mathrm{ddg} 289$

Heyser, C. J., McNaughton, C. H., Vishnevetsky, D., and Fienberg, A. A. (2013). Methylphenidate restores novel object recognition in DARPP-32 knockout mice. Behav. Brain Res. 253, 266-273. doi: 10.1016/j.bbr.2013.07.031

Huttenrauch, M., Salinas, G., and Wirths, O. (2016). Effects of long-term environmental enrichment on anxiety, memory, hippocampal plasticity and overall brain gene expression in C57BL6 mice. Front. Mol. Neurosci. 9:62. doi: $10.3389 /$ fnmol.2016.00062

Ignacak, M. L., Harbaugh, S. V., Dayyat, E., Row, B. W., Gozal, D., and Czyzyk-Krzeska, M. F. (2009). Intermittent hypoxia regulates RNA polymerase II in hippocampus and prefrontal cortex. Neuroscience 158, 1436-1445. doi: 10.1016/j.neuroscience.2008.11.025

Inoue, K., Okamoto, M., Shibato, J., Lee, M. C., Matsui, T., Rakwal, R., et al. (2015). Correction: long-term mild, rather than intense, exercise enhances adult hippocampal neurogenesis and greatly changes the transcriptomic profile of the hippocampus. PLoS ONE 10:e0133089. doi: 10.1371/journal.pone.0133089

Iwasaki, K., Ogawa, Y., Aoki, K., and Yanagida, R. (2012). Cerebral circulation during mild $+\mathrm{Gz}$ hypergravity by short-arm human centrifuge. J. Appl. Physiol. 112, 266-271. doi: 10.1152/japplphysiol.01232.2011

Jarome, T. J., and Helmstetter, F. J. (2014). Protein degradation and protein synthesis in long-term memory formation. Front. Mol. Neurosci. 7:61. doi: $10.3389 /$ fnmol.2014.00061

Kaouane, N., Porte, Y., Vallee, M., Brayda-Bruno, L., Mons, N., Calandreau, L., et al. (2012). Glucocorticoids can induce PTSD-like memory impairments in mice. Science 335, 1510-1513. doi: 10.1126/science. 1207615
Kim, E. J., Pellman, B., and Kim, J. J. (2015). Stress effects on the hippocampus: a critical review. Learn. Mem. 22, 411-416. doi: 10.1101/lm.037291.114

Leil, T. A., Ossadtchi, A., Nichols, T. E., Leahy, R. M., and Smith, D. J. (2003). Genes regulated by learning in the hippocampus. J. Neurosci. Res. 71, 763-768. doi: 10.1002/jnr.10541

Li, X. H., Chen, J. X., Yue, G. X., Liu, Y. Y., Zhao, X., Guo, X. L., et al. (2013). Gene expression profile of the hippocampus of rats subjected to chronic immobilization stress. PLoS ONE 8:e57621. doi: 10.1371/journal.pone.0057621

Lo, M. J., Kau, M. M., Cho, W. L., and Wang, P. S. (2000). Aging effects on the secretion of corticosterone in male rats. J. Investig. Med. 48, 335-342.

Longden, T. A., Dabertrand, F., Hill-Eubanks, D. C., Hammack, S. E., and Nelson, M. T. (2014). Stress-induced glucocorticoid signaling remodels neurovascular coupling through impairment of cerebrovascular inwardly rectifying K+ channel function. Proc. Natl. Acad. Sci. U.S.A. 111, 7462-7467. doi: 10.1073/pnas.1401811111

Marks, W. N., Fenton, E. Y., Guskjolen, A. J., and Kalynchuk, L. E. (2015). The effect of chronic corticosterone on fear learning and memory depends on dose and the testing protocol. Neuroscience 289, 324-333. doi: 10.1016/j.neuroscience.2015.01.011

McGaugh, J. L., and Roozendaal, B. (2002). Role of adrenal stress hormones in forming lasting memories in the brain. Curr. Opin. Neurobiol. 12, 205-210. doi: 10.1016/S0959-4388(02)00306-9

Micheau, J., Destrade, C., and Soumireu-Mourat, B. (1984). Time-dependent effects of posttraining intrahippocampal injections of corticosterone on retention of appetitive learning tasks in mice. Eur. J. Pharmacol. 106, 39-46. doi: 10.1016/0014-2999(84)90675-7

Mitani, K., Horii, A., and Kubo, T. (2004). Impaired spatial learning after hypergravity exposure in rats. Brain Res. Cogn. Brain Res. 22, 94-100. doi: 10.1016/j.cogbrainres.2004.08.002

Morel, J. L., Dabertrand, F., Porte, Y., Prevot, A., and MacRez, N. (2014). Up-regulation of ryanodine receptor expression increases the calciuminduced calcium release and spontaneous calcium signals in cerebral arteries from hindlimb unloaded rats. Pflugers Arch. 466, 1517-1528. doi: 10.1007/s00424-013-1387-9

Pearson-Leary, J., Osborne, D. M., and McNay, E. C. (2015). Role of glia in stressinduced enhancement and impairment of memory. Front. Integr. Neurosci. 9:63. doi: 10.3389/fnint.2015.00063

Petrak, J., Mravec, B., Jurani, M., Baranovska, M., Tillinger, A., Hapala, I., et al. (2008). Hypergravity-induced increase in plasma catecholamine and corticosterone levels in telemetrically collected blood of rats during centrifugation. Ann. N. Y. Acad. Sci. 1148, 201-208. doi: 10.1196/annals.1410.060

Pitman, D. L., Ottenweller, J. E., and Natelson, B. H. (1988). Plasma corticosterone levels during repeated presentation of two intensities of restraint stress: chronic stress and habituation. Physiol. Behav. 43, 47-55. doi: 10.1016/0031-9384(88)90097-2

Plaut, K., Maple, R. L., Wade, C. E., Baer, L. A., and Ronca, A. E. (2003). Effects of hypergravity on mammary metabolic function: gravity acts as a continuum. $J$. Appl. Physiol. 95, 2350-2354. doi: 10.1152/japplphysiol.00287.2003

Porte, Y., and Morel, J. L. (2012). Learning on Jupiter, learning on the Moon: the dark side of the G-force. Effects of gravity changes on neurovascular unit and modulation of learning and memory. Front. Behav. Neurosci. 6:64. doi: 10.3389/fnbeh.2012.00064

Porter, N. M., Bohannon, J. H., Curran-Rauhut, M., Buechel, H. M., Dowling, A. L., Brewer, L. D., et al. (2012). Hippocampal CA1 transcriptional profile of sleep deprivation: relation to aging and stress. PLoS ONE 7:e40128. doi: 10.1371/journal.pone.0040128

Rajkumar, A. P., Qvist, P., Lazarus, R., Lescai, F., Ju, J., Nyegaard, M., et al. (2015). Experimental validation of methods for differential gene expression analysis and sample pooling in RNA-seq. BMC Genomics 16:548. doi: 10.1186/s12864-015-1767-y

Reul, J. M., and De Kloet, E. R. (1985). Two receptor systems for corticosterone in rat brain: microdistribution and differential occupation. Endocrinology 117, 2505-2511. doi: 10.1210/endo-117-6-2505

Roozendaal, B., and McGaugh, J. L. (1997). Basolateral amygdala lesions block the memory-enhancing effect of glucocorticoid administration in the dorsal hippocampus of rats. Eur. J. Neurosci. 9, 76-83. doi: 10.1111/j.1460-9568.1997.tb01355.x 
Salehi, B., Cordero, M. I., and Sandi, C. (2010). Learning under stress: the invertedU-shape function revisited. Learn. Mem. 17, 522-530. doi: 10.1101/lm.1914110

Sasahara, A., Kasuya, H., Akagawa, H., Ujiie, H., Kubo, O., Sasaki, T., et al. (2007). Increased expression of ephrin A1 in brain arteriovenous malformation: DNA microarray analysis. Neurosurg. Rev. 30, 299-305. discussion: 305. doi: 10.1007/s10143-007-0087-3

Scheuer, D. A., Bechtold, A. G., and Vernon, K. A. (2007). Chronic activation of dorsal hindbrain corticosteroid receptors augments the arterial pressure response to acute stress. Hypertension 49, 127-133. doi: 10.1161/01.HYP.0000250088.15021.c2

Seo, J., Giusti-Rodriguez, P., Zhou, Y., Rudenko, A., Cho, S., Ota, K. T., et al. (2014). Activity-dependent p25 generation regulates synaptic plasticity and Abeta-induced cognitive impairment. Cell 157, 486-498. doi: 10.1016/j.cell.2014.01.065

Stankiewicz, A. M., Goscik, J., Majewska, A., Swiergiel, A. H., and Juszczak, G. R. (2015). The effect of acute and chronic social stress on the hippocampal transcriptome in mice. PLoS ONE 10:e0142195. doi: 10.1371/journal.pone.0142195

Stilling, R. M., Benito, E., Gertig, M., Barth, J., Capece, V., Burkhardt, S., et al. (2014). De-regulation of gene expression and alternative splicing affects distinct cellular pathways in the aging hippocampus. Front. Cell. Neurosci. 8:373. doi: 10.3389/fncel.2014.00373

Suri, D., Bhattacharya, A., and Vaidya, V. A. (2014). Early stress evokes temporally distinct consequences on the hippocampal transcriptome, anxiety and cognitive behaviour. Int. J. Neuropsychopharmacol. 17, 289-301. doi: $10.1017 / S 1461145713001004$

Tabatadze, N., McGonigal, R., Neve, R. L., and Routtenberg, A. (2014). Activitydependent Wnt 7 dendritic targeting in hippocampal neurons: plasticity- and tagging-related retrograde signaling mechanism? Hippocampus 24, 455-465. doi: $10.1002 /$ hipo.22239

Tadross, J. A., Patterson, M., Suzuki, K., Beale, K. E., Boughton, C. K., Smith, K. L., et al. (2010). Augurin stimulates the hypothalamopituitary-adrenal axis via the release of corticotrophin-releasing factor in rats. Br. J. Pharmacol. 159, 1663-1671. doi: 10.1111/j.1476-5381.2010. 00655.x

Tiwari, A., Schuiki, I., Zhang, L., Allister, E. M., Wheeler, M. B., and Volchuk, A. (2013). SDF2L1 interacts with the ER-associated degradation machinery and retards the degradation of mutant proinsulin in pancreatic beta-cells. J. Cell Sci. 126, 1962-1968. doi: 10.1242/jcs.117374
Tronche, C., Pierard, C., Coutan, M., Chauveau, F., Liscia, P., and Beracochea, D. (2010). Increased stress-induced intra-hippocampus corticosterone rise associated with memory impairments in middle-aged mice. Neurobiol. Learn. Mem. 93, 343-351. doi: 10.1016/j.nlm.2009.11.009

Udan-Johns, M., Bengoechea, R., Bell, S., Shao, J., Diamond, M. I., True, H. L., et al. (2014). Prion-like nuclear aggregation of TDP-43 during heat shock is regulated by HSP40/70 chaperones. Hum. Mol. Genet. 23, 157-170. doi: $10.1093 / \mathrm{hmg} / \mathrm{ddt} 408$

VanLoon (2016). Centrifuges for microgravity simulation. The reduced gravity paradigm. Front. Astron. Space Sci. 3:21. doi: 10.3389/fspas.2016.00021

Vernikos, J., and Schneider, V. S. (2010). Space, gravity and the physiology of aging: parallel or convergent disciplines? A mini-review. Gerontology 56, 157-166. doi: $10.1159 / 000252852$

Wang, J., Yuan, J., Pang, J., Ma, J., Han, B., Geng, Y., et al. (2016). Effects of chronic stress on cognition in male SAMP8 mice. Cell. Physiol. Biochem. 39, 1078-1086. doi: $10.1159 / 000447816$

Weng, L., Guo, X., Li, Y., Yang, X., and Han, Y. (2016). Apigenin reverses depression-like behavior induced by chronic corticosterone treatment in mice. Eur. J. Pharmacol. 774, 50-54. doi: 10.1016/j.ejphar.2016.01.015

Witt, S. N. (2013). Molecular chaperones, alpha-synuclein, and neurodegeneration. Mol. Neurobiol. 47, 552-560. doi: 10.1007/s12035-012-8325-2

Xu, N., Zhou, W. J., Wang, Y., Huang, S. H., Li, X., and Chen, Z. Y. (2015). Hippocampal Wnt3a is necessary and sufficient for contextual fear memory acquisition and consolidation. Cereb. Cortex 25, 4062-4075. doi: 10.1093/cercor/bhu121

Yang, W. M., and Lee, W. (2014). CTRP5 ameliorates palmitate-induced apoptosis and insulin resistance through activation of AMPK and fatty acid oxidation. Biochem. Biophys. Res. Commun. 452, 715-721. doi: 10.1016/j.bbrc.2014.08.145

Conflict of Interest Statement: The authors declare that the research was conducted in the absence of any commercial or financial relationships that could be construed as a potential conflict of interest.

Copyright (c) 2016 Pulga, Porte and Morel. This is an open-access article distributed under the terms of the Creative Commons Attribution License (CC BY). The use, distribution or reproduction in other forums is permitted, provided the original author(s) or licensor are credited and that the original publication in this journal is cited, in accordance with accepted academic practice. No use, distribution or reproduction is permitted which does not comply with these terms. 